\title{
CARACTERIZAÇÃO MINERALÓGICA E ALTERNATIVA PARA BENEFICIAMENTO DE LITOTIPOS MINERALIZADOS EM TERRAS RARAS DO COMPLEXO ALCALINO DE CATALÃO*
}

Francisco Gregianin Testa ' Angela Nair Avelar ${ }^{2}$ Ruberlan Gomes Silva ${ }^{2}$ Cássia Cristine Souza ${ }^{2}$

\section{Resumo}

Um estudo de caracterização foi conduzido para amostras mineralizadas em terras raras dos cinco principais litotipos do depósito de Catalão: Foscorito, Flogopitito, Bebedourito, Silexito e Cobertura. Os maiores teores de terras raras foram observados nas frações finas, predominando as terras raras leves, sendo acima de $95 \%$ em massa das terras raras totais. Frações granulométricas de cada litotipo foram submetidas a caracterização mineralógica, onde foram avaliadas as composições modais e suas associações mineralógicas, assim como a liberação da monazita por faixa granulométrica. A mineralogia presente nos litotipos é similar, embora com diferentes proporções. Confirmou-se que o principal mineral portador de terras raras em todos os litotipos é a monazita, porém suas associações e relações texturais podem variar. A mineralogia complexa torna tecnicamente inviável o uso de rotas de processos convencionais de concentração física, tais, como separação magnética e densitárias, além de flotação.

Palavras-chave: Caracterização; Terras raras; Fosfato; Monazita; Catalão.

\section{MINERALOGICAL CARACTERIZATION AND ALTERNATIVE TO CONCENTRATE THE RARE EARTH LITHOTYPES FROM ALCALINE COMPLEX OF CATALÃO - GO}

\begin{abstract}
A characterization study was conducted with five rare earth ore samples from the main lithotypes of Catalão deposit: Phoscorite, Phlogopitite, Bebedourite, Silexite and Cover. The fines particles have the higher rare earth grades, with predominance of light rare earth, corresponding to more than $95 \%$ of the rare earth total. The modal composition, mineral association and monazite liberation were determinate in the particle sizes fractions of each. The minerals determined in each sample were similar but in different concentrations. It was confirmed that monazite is the main rare earth bearing mineral for all the lithotypes, but its associations and textures are variable. The complex mineralogy becomes the use the conventional technics to concentrate rare earth mineral unavailable, like magnetic and density separation, besides flotation. Keywords: Characterization; Rare earth; Phosphate; Monazite; Catalão.
\end{abstract}

\section{INTRODUÇÃO}

As terras raras compreendem um grupo de 17 elementos químicos metálicos (Elementos/Óxidos de Terras Raras ETR/OTR) de ampla distribuição na crosta terrestre, mas em baixas concentrações. A aplicação desses elementos está voltada à produção de ímãs permanentes, circuitos eletroeletrônicos, catalisadores de gases de escapamento, equipamentos de laser, telefones celulares, corantes em vidros e cerâmicas, lentes de alta refração e ligas metálicas [I].

Com o aumento do uso dos ETR e a produção monopolizada pela China, responsável por cerca de $97 \%$

I Universidade de São Paulo - USP, São Paulo, SP, Brasil.

${ }^{2}$ Centro de Desenvolvimento Mineral da VALE, Santa Luiza, MG, Brasil. E-mail: angela.avelar@vale.com

* Uma versão deste trabalho foi apresentada no Encontro Nacional de Tratamento de Minérios e Metalurgia Extrativa, XXVI, Poços de Caldas, MG, Brasil, 18 a 22 de outubro de 2015. 
da produção mundial, a exploração dos minérios de terras raras tem ganhado importância. No Brasil os depósitos de terras raras mais importantes ocorrem em complexos carbonatíticos, principalmente associados aos depósitos de fosfato (Catalão, Araxá e Tapira), sendo um dos mais importantes o depósito de Catalão em Goiás.

Segundo Ribeiro [2], a região de Catalão apresenta um recurso de terras raras estimado em 119 milhões de toneladas, com teor de 5,5\% de ETR (considerando teor de corte de 2,0\% de ETR), sendo 79 milhões de toneladas desse recurso referente ao depósito Córrego do Garimpo.

O Complexo alcalino carbonatítico de Catalão encontra-se inserido na Província Ígnea do Alto Paranaíba (PIAP) que é formada por um conjunto de rochas carbonatíticas, kimberlíticas e kamafugíticas que ocorrem na forma de diques, pipes, plugs, diatremas, derrames de lavas, depósitos piroclásticos e grandes complexos plutônicos [3]. Os depósitos minerais do complexo resultaram de três processos geológicos, especificamente, o magmatismo, o metassomatismo e o intemperismo (Figura I).

O principal mineral portador de terras raras na região de Catalão é a monazita [4]. A gênese da mineralização de monazita em Catalão é carbo-hidrotermal impostas sobre três diferentes suítes de rochas magmáticas, sendo elas: Série Bebedourítica, Série Foscorítica e Série Carbonatítica [2]. O metassomatismo foi o agente principal da mineralização de monazita, através de fluidos carbo-hidrotermais carregados em ETR, possivelmente liberadas durante a transformação metassomática da perovskita em anatásio [2].

O processamento dos minérios de terras raras normalmente envolve o beneficiamento mineral, com concentração das terras raras via separação gravimétrica ou flotação, seguido de rotas ácida ou alcalina, determinadas pela natureza do mineral minério e minerais de ganga eventualmente presentes $[5,6]$. No depósito de Catalão, a mineralogia complexa, devido a presença de cristais de pequenas dimensões e a associação do mineral portador de terras raras com outros minerais, torna o uso de processo convencionais de beneficiamento inviáveis do ponto de vista técnico [7].

Este trabalho apresenta a caracterização de cinco amostras de terras raras do depósito de Catalão, com base nos resultados obtidos foi proposta uma rota de beneficiamento para minério de terras raras de Catalão previamente às etapas de extração dos ETR.

\section{MATERIAL E MÉTÓDOS}

Cinco amostras, uma de cada litotipo, foram coletadas no depósito de terras raras de Catalão. As amostras foram enviadas para o Centro de Desenvolvimento Mineral da Vale (CDM) para caracterização e estudo de rotas de processos. A denominação de cada amostra foi definida de acordo com o litotipo onde a amostra foi coletada, sendo elas Foscorito, Flogopitito, Bebedourito, Silexito e Cobertura.

Cada amostra foi homogeneizada em pilha alongada e quarteada em quarteadores rotativos. A distribuição granulométrica foi realizada em peneiras quadradas $(8000,4000,2000,1000,500,300,150,100,74,38 \mu \mathrm{m})$ onde os retidos em cada peneira foram submetidos a análise química. A fração passante da peneira com menor abertura $(38 \mu \mathrm{m})$ teve a distribuição granulométrica determinada por cyclosizer, os produtos das frações geradas no cyclosizer foram submetidas a análise química.

As análises químicas foram realizadas no CDM, utilizando ICP-OES (espectrometria de emissão atômica com fonte de plasma indutivamente acoplado) para determinação dos principais elementos ou óxidos compostos e ICP-MS (espectrometria de massa atômica com fonte de plasma indutivamente acoplado) para determinação dos elementos

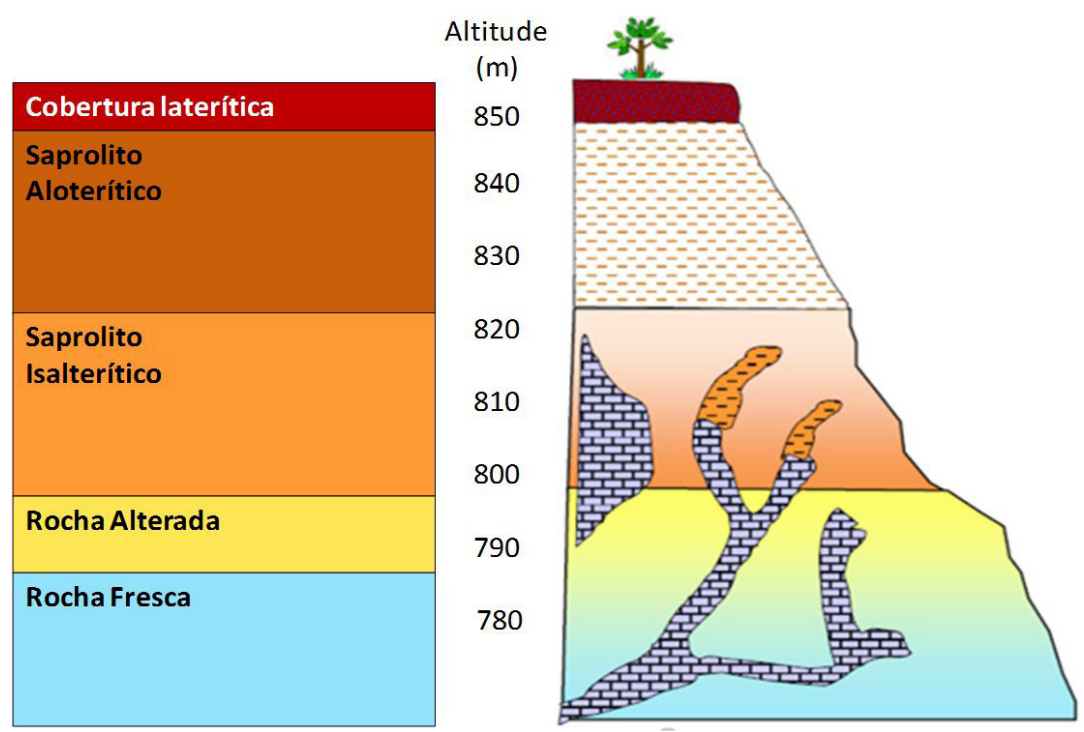

Figura I. Perfil de intemperismo do Complexo de Catalão I de acordo com Oliveira e Imbernon (1998) adaptado por Ribeiro [2]. 
terras raras. As análises de gadolínio $(\mathrm{Gd})$ e térbio $(\mathrm{Tb})$ não estão contempladas nesse estudo.

Para estudo de caracterização mineralógica foram confeccionadas seções polidas para cada uma das amostras ROM (run of mine), assim como as frações retidas nas peneiras, para análise no sistema automatizado de análise mineralógica QEMSCAN e microscópio eletrônico de varredura (MEV). $A$ amostra de Silexito foi a única submetida a britagem em britador de rolos lisos com abertura de $8 \mathrm{~mm}$, antes de submetida a análise química.

Buscando concentrar terras raras, foram realizados ensaios de separação magnética com a fração $<74 \mu \mathrm{m}$ dos litotipos Bebedourito e Cobertura com objetivo de remover os minerais portadores de ferro e elevar os teores de terras raras nas frações não magnéticas. Foi utilizado o equipamento separador magnético tipo Placa Jones, fabricado pela Eriez, com matriz de placas ranhuradas com abertura de $0,75 \mathrm{~mm}$. Nessa abertura não é possível introduzir a sonda para medida do campo magnético. Foram testados três níveis de corrente, $3 \mathrm{~A}$, que proporciona um campo próximo de 1.000 Gauss, 4 A, campo próximo de 12.000 Gauss, e 20 A que proporciona um campo acima de 18.000 Gauss. O procedimento adotado para o teste consistia em submeter a fração não magnética do campo mais baixo a uma separação magnética em um campo mais alto, conforme mostrado na Figura 2.

\section{RESULTADOS E DISCUSSÃO}

Os resultados obtidos no estudo mostraram grande semelhança entre os litotipos, com exceção do Silexito que apresentou aspecto compacto, enquanto as demais amostras apresentaram granulometria fina, decorrente do intemperismo que o depósito foi submetido. Nas Tabelas I, 2, 3, 4 e 5 são apresentados os resultados das análises químicas das

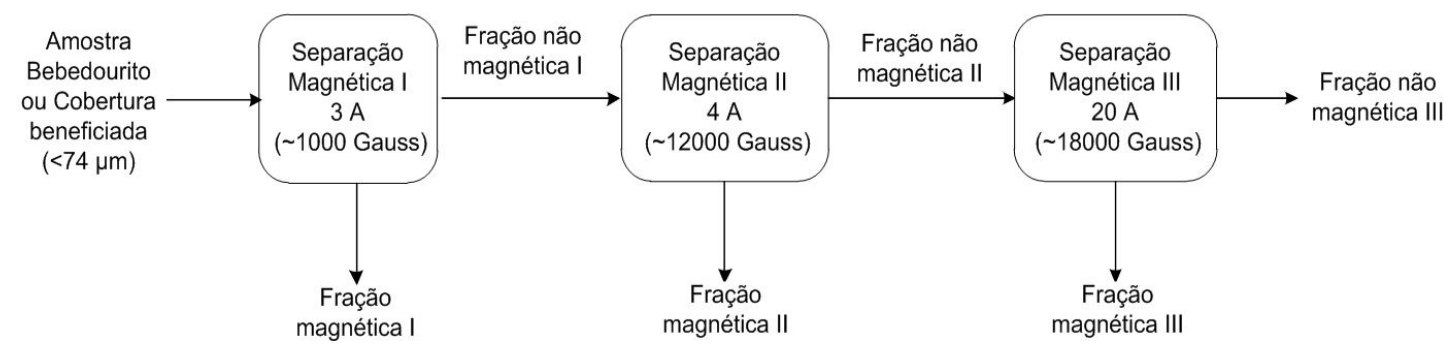

Figura 2. Diagrama de blocos utilizado nos ensaios de separação magnética.

Tabela I. Teores por faixa da amostra de minério Foscorito

\begin{tabular}{|c|c|c|c|c|c|c|c|c|}
\hline \multirow{2}{*}{ Fração $(\mu \mathrm{m})$} & \multirow{2}{*}{ Massa (\%) } & \multicolumn{7}{|c|}{ Teores (\%) } \\
\hline & & OTR & $\mathrm{Fe}_{2} \mathrm{O}_{3}$ & $\mathrm{SiO}_{2}$ & $\mathrm{Al}_{2} \mathrm{O}_{3}$ & $\mathrm{CaO}$ & $\mathbf{P}_{2} \mathbf{O}_{5}$ & $\mathrm{TiO}_{2}$ \\
\hline ROM & 100,0 & 2,79 & 39,13 & 18,55 & 3,18 & $\mathrm{I}, 79$ & 4,32 & 20,61 \\
\hline+4000 & 12,9 & $\mathrm{I}, 47$ & 41,8 & 27,38 & 1,97 & $\mathrm{I}, 85$ & 3,82 & 14,2 \\
\hline+1000 & 16,0 & $|, 3|$ & 47,4 & 18,45 & 1,58 & $\mathrm{I}, 56$ & 2,79 & 21,4 \\
\hline+300 & 14,0 & $|, 3|$ & 43,2 & 16,12 & 1,45 & $\mathrm{I}, 37$ & 2,41 & 28,6 \\
\hline+150 & 9,1 & 1,54 & 38,2 & 16,64 & 1,95 & 1,25 & 2,79 & 29,9 \\
\hline+74 & 8,6 & 1,95 & 34,0 & 18,12 & 2,58 & $\mathrm{I}, 30$ & 3,29 & 28,1 \\
\hline+38 & 8,7 & 2,73 & 31,6 & 18,72 & 3,64 & 1,69 & 4,42 & 25,8 \\
\hline+8 & 11,7 & 5,60 & 29,9 & 19,33 & 4,31 & 2,63 & 6,82 & 19,3 \\
\hline-8 & 19,0 & 6,22 & 39,2 & 14,97 & 6,57 & 2,26 & 6,95 & 9,0 \\
\hline
\end{tabular}

Tabela 2. Teores por faixa da amostra de minério Flogopitito

\begin{tabular}{|c|c|c|c|c|c|c|c|c|}
\hline \multirow{2}{*}{ Fração $(\mu \mathrm{m})$} & \multirow{2}{*}{ Massa (\%) } & \multicolumn{7}{|c|}{ Teores (\%) } \\
\hline & & OTR & $\mathrm{Fe}_{2} \mathrm{O}_{3}$ & $\mathrm{SiO}_{2}$ & $\mathrm{Al}_{2} \mathrm{O}_{3}$ & $\mathrm{CaO}$ & $\mathbf{P}_{2} \mathbf{O}_{5}$ & $\mathrm{TiO}_{2}$ \\
\hline ROM & 100,0 & 2,38 & 34,1 & 19,50 & 2,96 & 6,75 & 6,15 & 15,5 \\
\hline+4000 & I5, I & 1,12 & 26,7 & 30,58 & 0,70 & 12,98 & 8,51 & 8,6 \\
\hline+1000 & 20,7 & $\mathrm{I}, 28$ & 45,8 & 15,14 & 0,87 & 6,19 & 4,68 & 20,5 \\
\hline+300 & 11,7 & 1,25 & 35,5 & 18,87 & 1,46 & 7,53 & 5,96 & 20,3 \\
\hline+150 & 9,5 & 1,33 & 33,0 & 17,82 & 2,17 & 6,03 & 4,98 & 20,6 \\
\hline+74 & 9,7 & 1,55 & 29,9 & 18,87 & 2,79 & 5,76 & 5,15 & 19,9 \\
\hline+38 & 9,0 & 2,21 & 29,1 & 18,04 & 3,75 & 5,46 & 6,06 & 19,4 \\
\hline+8 & 7,8 & 4,13 & 27,5 & 17,60 & 4,38 & 6,28 & 8,70 & 14,4 \\
\hline-8 & 16,6 & 6,07 & 34,2 & 18,32 & 8,16 & 3,11 & 6,06 & 5,2 \\
\hline
\end{tabular}

Tecnol. Metal. Mater. Miner., São Paulo, 
Tabela 3. Teores por faixa da amostra de minério Bebedourito

\begin{tabular}{|c|c|c|c|c|c|c|c|c|}
\hline \multirow{2}{*}{ Fração $(\mu \mathrm{m})$} & \multirow{2}{*}{ Massa (\%) } & \multicolumn{7}{|c|}{ Teores (\%) } \\
\hline & & OTR & $\mathrm{Fe}_{2} \mathrm{O}_{3}$ & $\mathrm{SiO}_{2}$ & $\mathrm{Al}_{2} \mathrm{O}_{3}$ & $\mathrm{CaO}$ & $\mathbf{P}_{2} \mathbf{O}_{5}$ & $\mathrm{TiO}_{2}$ \\
\hline ROM & 100,0 & 2,28 & $4 I, I$ & 21,50 & 2,62 & 0,95 & 2,10 & 23,6 \\
\hline+4000 & 10,6 & 0,93 & 28,4 & 51,17 & 0,77 & 0,95 & 0,96 & 14,0 \\
\hline+1000 & 15,3 & $\mathrm{I}, 03$ & 48,7 & 19,93 & 0,63 & 0,95 & 0,90 & 23,5 \\
\hline+300 & 18,0 & 1,16 & 47,6 & 17,40 & 0,77 & 0,95 & $\mathrm{I}, 04$ & 28,4 \\
\hline+150 & 11,3 & $|, 4|$ & 44,3 & 17,40 & $\mathrm{I}, 28$ & 0,95 & $\mathrm{I}, 27$ & 28,5 \\
\hline+74 & 9,0 & $\mathrm{I}, 74$ & 39,2 & 18,33 & 2,00 & 0,95 & $\mathrm{I}, 64$ & 31,1 \\
\hline+38 & 7,6 & 2,31 & 32,7 & 20,27 & 2,91 & 0,95 & 2,16 & 31,6 \\
\hline+8 & 12,2 & 3,60 & 32,9 & 18,89 & 3,32 & 0,95 & 3,36 & 28,6 \\
\hline-8 & 16,0 & 5,40 & 43,7 & 15,18 & 8,44 & 0,95 & 5,06 & 9,3 \\
\hline
\end{tabular}

Tabela 4. Teores por faixa da amostra de minério Silexito

\begin{tabular}{|c|c|c|c|c|c|c|c|c|}
\hline \multirow{2}{*}{ Fração $(\mu \mathrm{m})$} & \multirow{2}{*}{ Massa (\%) } & \multicolumn{7}{|c|}{ Teores (\%) } \\
\hline & & OTR & $\mathrm{Fe}_{2} \mathrm{O}_{3}$ & $\mathrm{SiO}_{2}$ & $\mathrm{Al}_{2} \mathrm{O}_{3}$ & $\mathrm{CaO}$ & $\mathbf{P}_{2} \mathbf{O}_{5}$ & $\mathrm{TiO}_{2}$ \\
\hline ROM & 100,0 & 5,88 & 9,2 & 72,30 & 0,43 & $\mathrm{I}, 27$ & 3,66 & 0,6 \\
\hline+4000 & 23,1 & 4,91 & 6,6 & 78,37 & 0,18 & 0,95 & 2,82 & 0,1 \\
\hline+1000 & 48,3 & 4,55 & 7,1 & 79,60 & 0,23 & 0,95 & 2,61 & 0,3 \\
\hline+300 & 12,8 & 5,88 & 10,6 & 69,40 & 0,41 & 2,02 & 4,35 & 0,9 \\
\hline+150 & 4,5 & 5,95 & 12,7 & 61,11 & 0,62 & 2,03 & 4,53 & 1,9 \\
\hline+74 & $\mathrm{I}, 4$ & 7,15 & 14,2 & 54,11 & 0,92 & $\mathrm{I}, 82$ & 4,99 & 2,8 \\
\hline+30 & 2,5 & 8,51 & 16,0 & 48,55 & 1,04 & $\mathrm{I}, 84$ & 5,86 & 3,5 \\
\hline+8 & 3,8 & 15,15 & 16,6 & 38,62 & $\mathrm{I}, 73$ & 2,31 & 9,79 & $\mathrm{I}, 7$ \\
\hline-8 & 3,6 & 17,74 & 30,1 & 18,93 & 2,70 & 2,17 & 11,19 & 0,6 \\
\hline
\end{tabular}

Tabela 5. Teores por faixa da amostra de minério Cobertura

\begin{tabular}{|c|c|c|c|c|c|c|c|c|}
\hline \multirow{2}{*}{ Fração $(\mu \mathrm{m})$} & \multirow{2}{*}{ Massa (\%) } & \multicolumn{7}{|c|}{ Teores (\%) } \\
\hline & & OTR & $\mathrm{Fe}_{2} \mathrm{O}_{3}$ & $\mathrm{SiO}_{2}$ & $\mathrm{Al}_{2} \mathrm{O}_{3}$ & $\mathrm{CaO}$ & $\mathbf{P}_{2} \mathbf{O}_{5}$ & $\mathrm{TiO}_{2}$ \\
\hline ROM & 100,0 & 2,38 & 45,7 & 14,37 & 5,78 & 0,95 & 2,98 & 19,7 \\
\hline+4000 & 16,6 & $\mathrm{I}, 28$ & 54,5 & $|2,0|$ & 3,67 & 0,98 & 2,09 & 18,2 \\
\hline+1000 & 22,5 & $\mathrm{I}, 26$ & 61,2 & 5,85 & 2,58 & 0,95 & 1,52 & 21,8 \\
\hline+300 & 12,1 & 2,05 & 46,8 & 13,19 & 4,36 & 0,95 & 2,71 & 23,6 \\
\hline+150 & 10,5 & 2,16 & $4 I, 7$ & $|8,0|$ & 5,21 & 0,95 & 2,92 & 22,7 \\
\hline+74 & 10,0 & 2,43 & 36,5 & 21,54 & 5,91 & 0,95 & 3,25 & 21,9 \\
\hline+38 & 8,8 & 2,87 & 31,8 & 23,18 & 7,34 & 0,95 & 3,79 & 20,5 \\
\hline+8 & 7,7 & 3,24 & 29,8 & 23,03 & 7,57 & 0,95 & 4,05 & 20,2 \\
\hline-8 & 11,8 & 5,67 & 35,2 & 13,65 & $|4,4|$ & 0,95 & 5,78 & 8,5 \\
\hline
\end{tabular}

amostras de cada litotipo e das massas retidas em cada fração granulométrica. $\mathrm{O}$ teor de $\mathrm{Fe}_{2} \mathrm{O}_{3}$ foi o mais abundante em todas as amostras, seguido de $\mathrm{TiO}_{2}$ e $\mathrm{SiO}_{2}$ com exceção do Silexito que apresentou predominância de $\mathrm{SiO}_{2}$. Todas as amostras apresentaram teores de $\mathrm{P}_{2} \mathrm{O}_{5}$ significativos e teor elevado de $\mathrm{CaO}$ apenas na amostra de Flogopitito, indicando que o fósforo não necessariamente está associado somente a monazita, ele também pode estar relacionado a presença de minerais do grupo da apatita e fosfatos aluminosos do grupo da crandalita.

A tendência de enriquecimento de OTR nas frações finas é observada em todos os litotipos, com maior intensidade na amostra de Silexito, porém a massa da fração fina é muito pequena nessa amostra, apenas $3,6 \%$ da massa é menor que $8 \mu \mathrm{m}$.

A Figura 3 apresenta as distribuições em massa total, dos OTR, $\mathrm{Fe}_{2} \mathrm{O}_{3}, \mathrm{SiO}_{2}, \mathrm{Al}_{2} \mathrm{O}_{3}$ e $\mathrm{MnO}_{2}$ nas frações passantes. Observa-se que as maiores quantidades dos deletérios $\mathrm{Fe}_{2} \mathrm{O}_{3}, \mathrm{SiO}_{2}$ e $\mathrm{MnO}_{2}$ são eliminados nas frações maiores que $74 \mu \mathrm{m}$. As distribuições dos OTR e de $\mathrm{Al}_{2} \mathrm{O}_{3}$ são similares, ou seja, distribuiem-se quase que na mesma proporção nas frações granulométricas passantes.

Na Figura 4 são apresentados a composição mineralógica para cada um dos litotipos, obtidos através de análise em QEMSCAN. A composiçao mineralógica é praticamente a mesma, com significativas variações em 


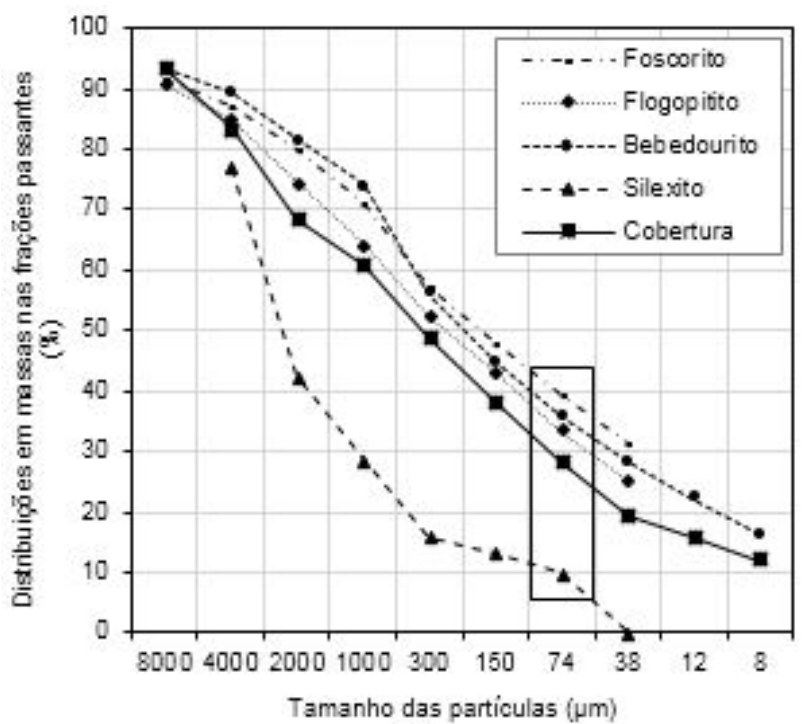

(a)

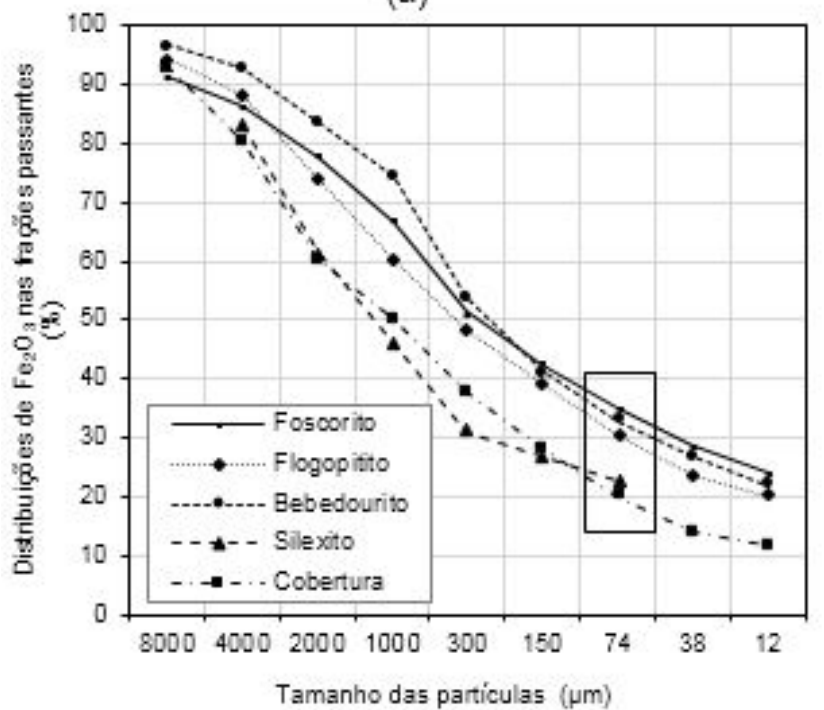

(c)

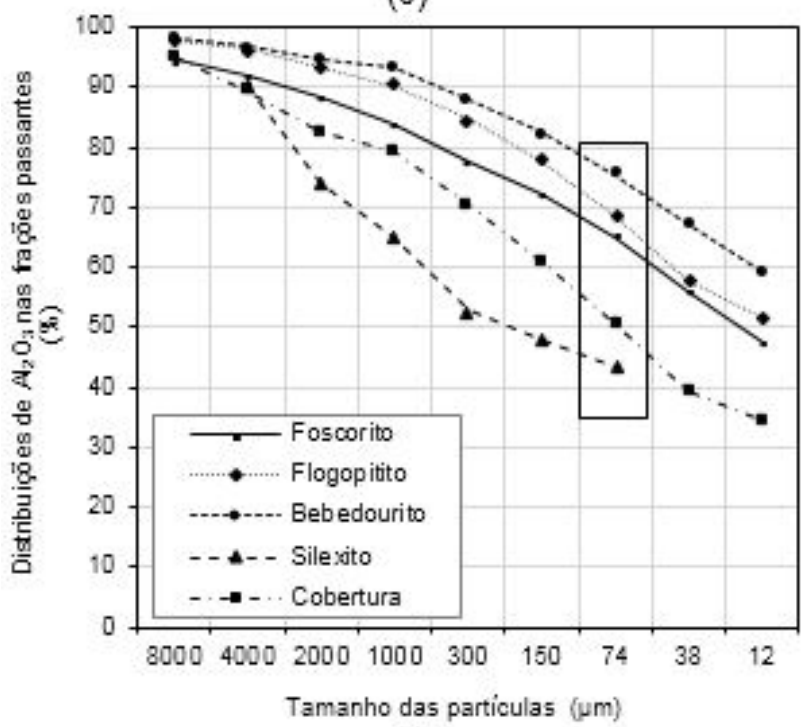

(e)

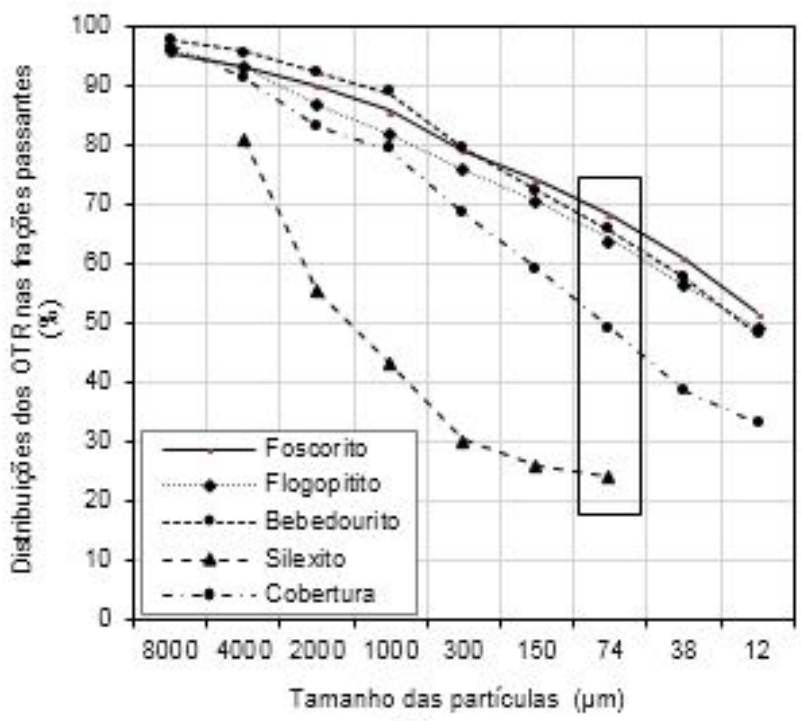

(b)

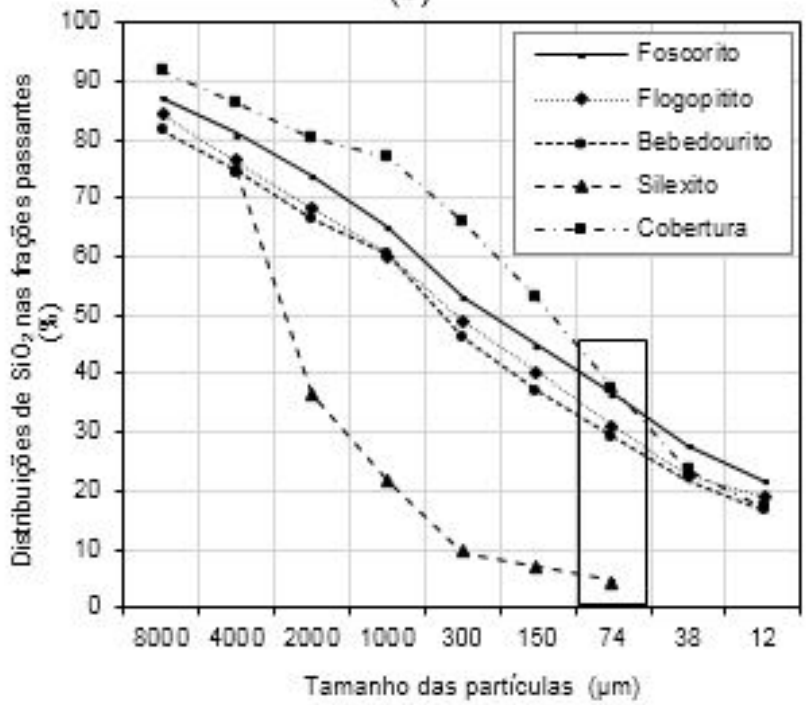

(d)

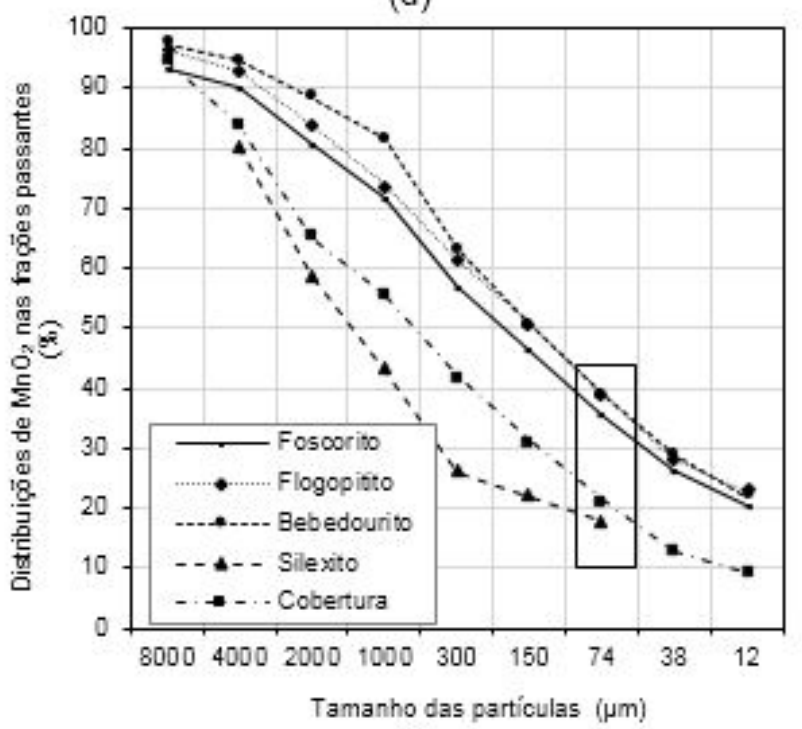

(f)

Figura 3. Distribuições em massa (a), OTR (b), $\mathrm{Fe}_{2} \mathrm{O}_{3}(\mathrm{c}), \mathrm{SiO}_{2}(\mathrm{~d}), \mathrm{Al}_{2} \mathrm{O}_{3}(\mathrm{e})$ e $\mathrm{MnO}_{2}$ (f) nas frações granulométricas passantes. 
sua distribuição modal. O Silexito é o litotipo que mais se diferencia dos outros quanto a composição mineralógica, devido a elevada presença de quartzo é resposánvel pela característica compacta observada nesse litotipo. Os demais apresentam valores mais elevados de minerais de ferro e titânio. E no caso, do flogopitito e foscorito, ainda encontra-se apatita preservada.

$\mathrm{Na}$ Figura 5 são apresentadas imagens geradas em microscópio eletrônico de varredura ilustrando as principais associações minerais da monazita. Na primeira imagem (A), da amostra Bebedourito, é apresentado o aspecto típico de ocorrência da monazita, intercrescida com minerais de ganga (anatásio, ilmenita e óxidos de ferro). Já na segunda imagem (B) é apresentada uma partícula liberada de monazita na amostra Silexito, mesmo quando liberada a partícula é formada por pequenos cristais e elevada porosidade. Nas demais litologias também ocorrem associações semelhantes.

$\mathrm{Na}$ Figura 6 são apresentadas imagens feitas com as amostras de Foscorito e Flogopitio, mostrando a monazita associada à anatásio, crandalita e minerais de ferro.

Devido ao fato dos minerais portadores de terras raras estarem intimamente associados aos minerais de ganga, a concentração da monazita é dificultada. A fração fina $(<74 \mu \mathrm{m})$ apresenta um enriquecimento significativo em comparação com a amostra global, e buscando enriquecer ainda mais as frações finas das amostras de Bebedourito e Cobertura foram submetidas a separação magnética em 3A (I000 Gauss), 4A (I 2000 Gauss) e 20A (I8000 Gauss).

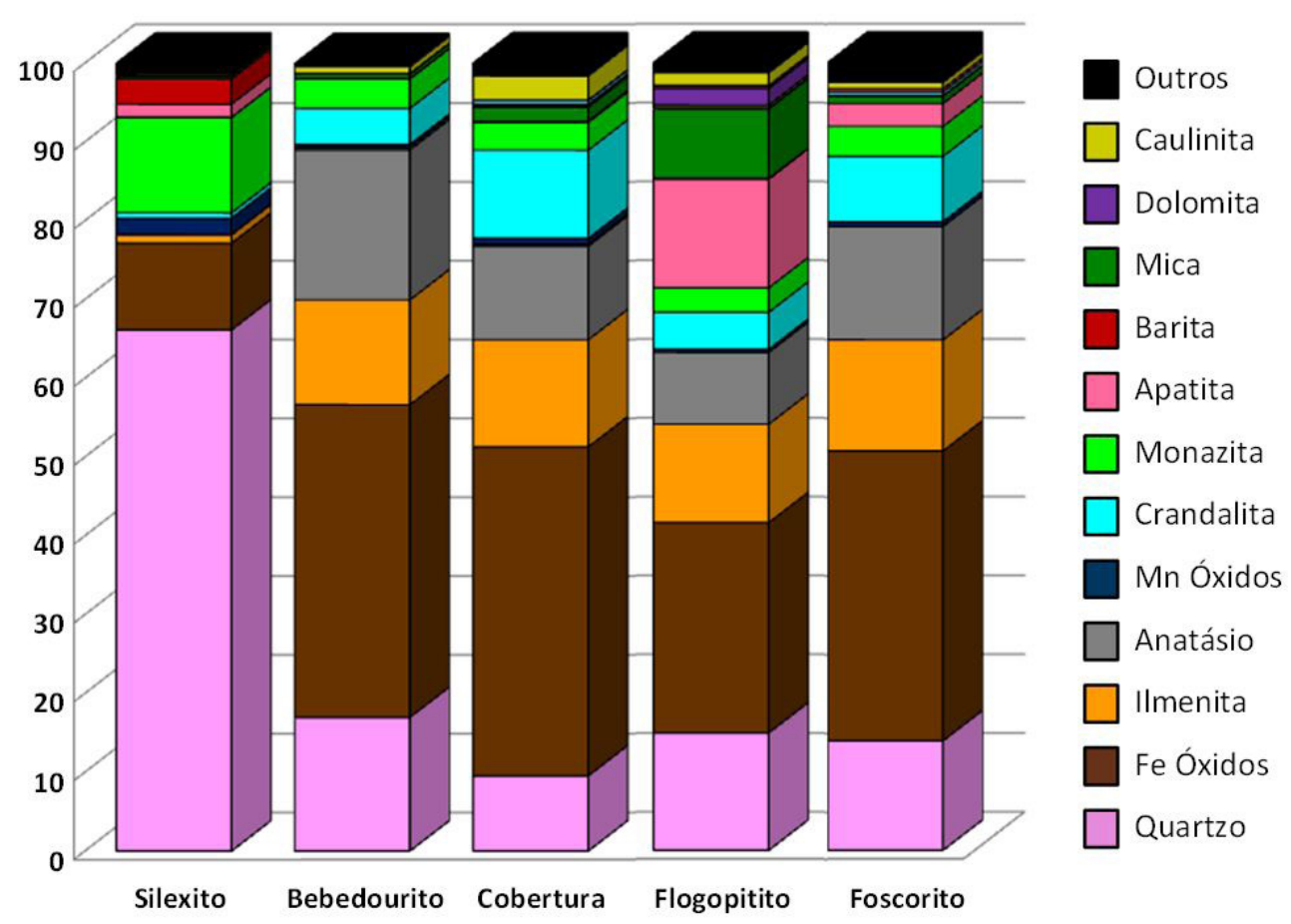

Figura 4. Distribuição dos minerais por litotipos.
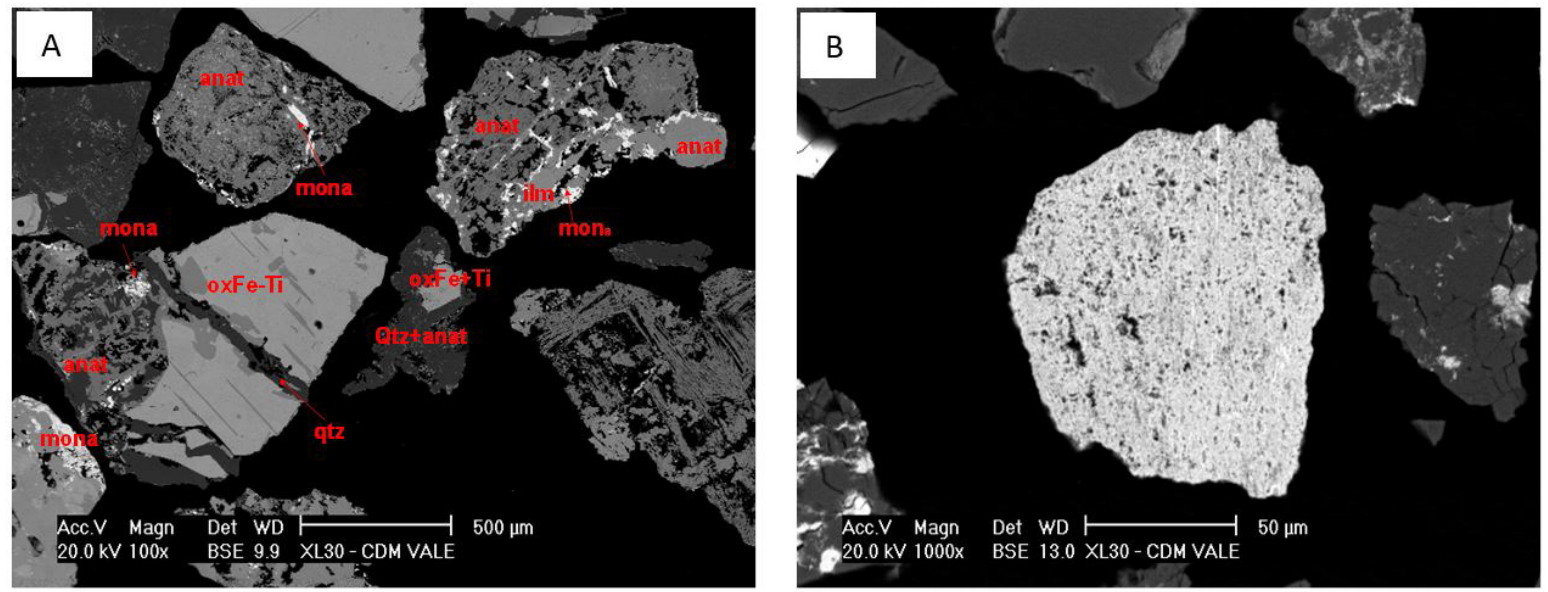

Figura 5. Imagens eletrônicas da monazita e suas associações nas amostras de (A) Bebedourito e (B) Silexito. 

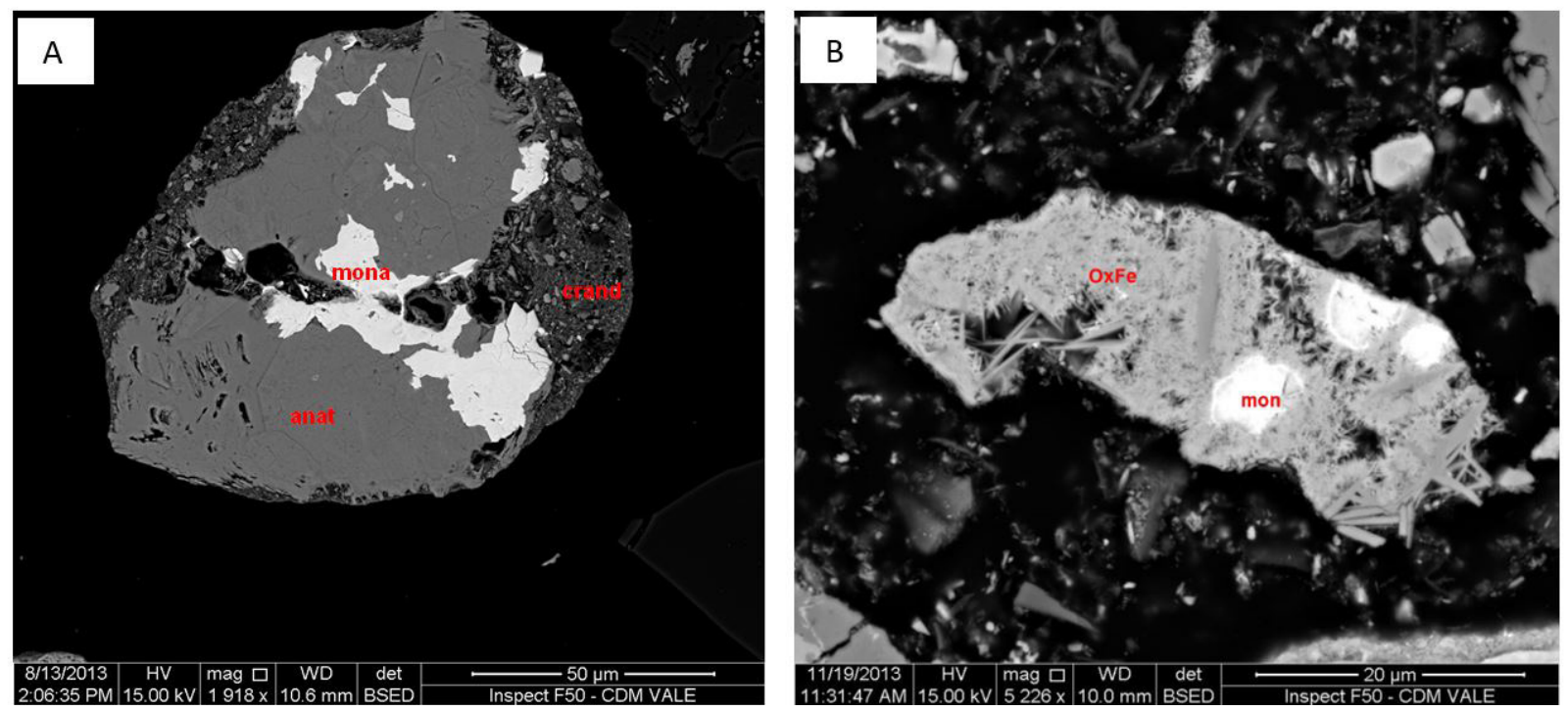

Figura 6. Imagens eletrônicas da monazita e suas associações nas amostras de (A) Foscorito e (B) Flogopitito.

Tabela 6. Resultados dos ensaios de separação magnética

\begin{tabular}{|c|c|c|c|c|c|c|c|c|c|c|c|c|c|c|}
\hline \multirow[b]{2}{*}{ Litologia } & \multicolumn{2}{|c|}{ Alimentação } & \multicolumn{4}{|c|}{$\begin{array}{c}\text { Fração não magnética I } \\
3 \text { A }\end{array}$} & \multicolumn{4}{|c|}{$\begin{array}{c}\text { Fração não magnética II } \\
4 \mathrm{~A}\end{array}$} & \multicolumn{4}{|c|}{$\begin{array}{c}\text { Fração não magnética II } \\
20 \mathrm{~A}\end{array}$} \\
\hline & $\begin{array}{l}\text { OTR } \\
\text { (\%) }\end{array}$ & $\begin{array}{l}\mathrm{Fe} \\
(\%)\end{array}$ & $\begin{array}{l}\text { OTR } \\
(\%)\end{array}$ & $\begin{array}{l}\mathrm{Fe} \\
(\%)\end{array}$ & $\begin{array}{c}\text { Rec. } \\
\text { Massa } \\
(\%) \\
\end{array}$ & $\begin{array}{c}\text { Rec. } \\
\text { OTR } \\
(\%) \\
\end{array}$ & $\begin{array}{c}\text { OTR } \\
\text { (\%) }\end{array}$ & $\begin{array}{l}\mathrm{Fe} \\
(\%)\end{array}$ & $\begin{array}{c}\text { Rec. } \\
\text { Massa } \\
(\%) \\
\end{array}$ & $\begin{array}{c}\text { Rec. } \\
\text { OTR } \\
(\%) \\
\end{array}$ & $\begin{array}{c}\text { OTR } \\
\text { (\%) }\end{array}$ & $\begin{array}{l}\mathrm{Fe} \\
(\%)\end{array}$ & $\begin{array}{c}\text { Rec. } \\
\text { Massa } \\
(\%) \\
\end{array}$ & $\begin{array}{l}\text { Rec. } \\
\text { OTR } \\
(\%) \\
\end{array}$ \\
\hline Bebedourito & 4,50 & 20,4 & 4,88 & & 89,8 & 97,3 & 4, & 24,0 & 97,8 & 98,7 & 3,1 & 22,5 & 97,0 & 98,5 \\
\hline Cobertura & 4,63 & 22,4 & 4,62 & 21,5 & $4 I, 5$ & 41,6 & 4,70 & 21,5 & 86,1 & 87,3 & 4,47 & 16,9 & 89,5 & 91,4 \\
\hline
\end{tabular}

Rec. Massa: Recuperação em massa e Rec. OTR: Recuperação dos OTR (Óxidos de Terras Raras).

Tabela 7. Teores dos óxidos de terras raras de cada litotipo

\begin{tabular}{|c|c|c|c|c|c|}
\hline Resultados & Foscorito & Flogopitito & Bebedourito & Silexito & Cobertura \\
\hline Teor de OTR na alimentação (\%) & 2,79 & 2,38 & 2,28 & 5,88 & 2,38 \\
\hline Recuperação em massa (\%) & 39 & 33 & 36 & 100 & 28 \\
\hline Teor de OTR do concentrado (\%) & 5,26 & 4,58 & 4,13 & 5,88 & 4,14 \\
\hline Fator de enriquecimento em OTR & 1,89 & 1,92 & I,8I & 1,00 & $\mathrm{I}, 74$ \\
\hline Recuperação de OTR (\%) & 70 & 64 & 50 & 100 & 49 \\
\hline
\end{tabular}

Os resultados são apresentados na Tabela 6. O enriquecimento em OTR é muito baixo nas frações não magnéticas mesmo quando são utilizados campos magnéticos elevados (20 A). Por exemplo, nos ensaios com Bebedourito com corrente de $20 \mathrm{~A}$, o teor de OTR aumentou apenas $4 \%$, passando de $4,93 \%$ para $5,13 \%$. A baixa seletividade se deve a presença de monazita pouco liberada [7] e sua íntima associação aos minerais de ferro.

O enriquecimento de terras raras pode ser obtido através de um corte granulométrico e aproveitamento das frações finas $<74 \mu \mathrm{m}$, com exceção do litotipo Silexito que apresenta baixa quantidade de finos, sugerindo-se para este uma moagem de todo minério $100 \%$ menor que $300 \mu \mathrm{m}$ e incorporação na fração $<74 \mu \mathrm{m}$ dos demais litotipos. Os resultados desse processo são apresentados na Tabela 7.

\section{CONCLUSÕES}

Os litotipos Foscorito, Flogopitito, Bebedourito e Cobertura apresentaram similaridades de teores e distribuições granulométricas, com elevada quantidade de finos, enquanto que o Silexito apresentou granulometria grosseira. Os teores dos OTR nas amostras variaram entre 2,28 a $5,88 \%$ com enriquecimento de terras raras nas frações finas, sendo predominantes as terras raras leves, denominadas aqui de $\mathrm{La}, \mathrm{Ce}, \mathrm{Nd}$ e $\operatorname{Pr}$ ( $95 \%$ em massa das terras raras totais). Os minerais presentes em cada litotipo são similares, porém com proporções diferentes, sendo os principais minerais o quartzo, óxi-hidróxidos de ferro, ilmenita, anatásio, apatita, monazita, flogopita/vermiculita e minerais do grupo da crandalita. O principal mineral portador de terras raras nas amostras é a monazita, porém suas associações e relações 
texturais variam para cada litotipo. Em menor proporção é verificada a presença de terras raras nos fosfatos aluminosos do grupo da crandalita. Os minerais de OTR geralmente encontram-se associados aos óxi-hidróxidos de ferro, anatásio,

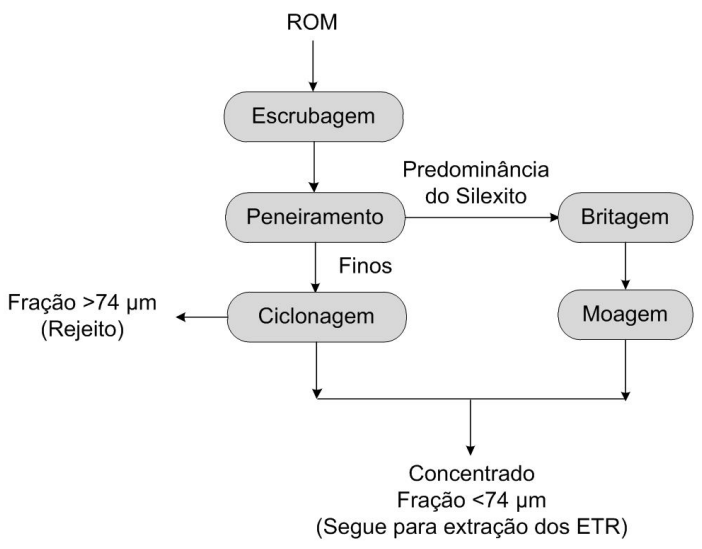

Figura 7. Fluxograma de concentração de OTR previamente ao uso da rota ácida. quartzo e fosfatos aluminosos e apatita, variando de acordo com a litotipo sobre o qual ocorreu a mineralização de terras raras. A mineralogia complexa impede o uso de técnicas convencionais, tais como separação magnética e densitária, além de flotação para concentração do mineral portador das terras raras. Devido ao enriquecimento natural das terras raras nas frações finas é sugerido o aproveitamento do material abaixo que $74 \mu \mathrm{m}$, obtendo-se nos finos teores próximos a $5 \%$ de OTR e recuperações de $60 \%$ de terras raras. A partir dos resultados encontrados para essas cinco amostras, propõe-se o fluxograma (Figura 7) para concentração dos OTR previamente ao uso da rota ácida ou alcalina na extração.

\section{Agradecimentos}

Os autores agradecem à Vale e à Vale Fertilizantes, por permitirem a publicação desse estudo.

\section{REFERÊNCIAS}

I Rocio MAR, Silva MM, Carvalho PSL, Cardoso JGR. Terras-raras: situação atual e perspectivas. BNDES Setorial. 2012;35:369-420.

2 Ribeiro CC. Geologia, geometalurgia, controles e gênese dos depósitos de fósforo, terras raras e titânio do complexo carbonatítico Catalão I, GO [tese de doutorado]. Brasília: Instituto de Geociências, Universidade de Brasília, 2008.

3 Gibson SA, Thompson RN, Leonardos OH, Dickin AP, Mitchell JG. The Late Cretaceous impact of the Trindade mantle plume - evidence from large-volume, mafic, potassic magmatism in SE Brazil. Journal of Petrology. 1995;36(I): 189-229. http://dx.doi.org/10.1093/petrology/36.I.I89.

4 Tassinari ML, Kahn H, Ratti G, Sant'agostino LM, Barros LAF, Mortagua VJG. Characterization of the rare earth ore deposit from Corrego do Garimpo, GO, Brazil. In VI Southern Hemisphere Meeting on Mineral Technology. In Anais do XVII Encontro Nacional de Tratamento de Minérios e Metalurgia Extrativa. Rio de Janeiro; 200I. p. 3-8. Vol. I.

5 Gupta CK, Krishnamurthy N. Resource processing: extractive metallurgy of rare earths. Londres: CRC Press; 2004. p. I33-192.

6 Krein OE, Samsonov GV, Zelikman AN. The rare earth metals (Lanthanides). Israel: Israel Program for Scientific Translations; 1966. Metallurgy of rare metals; p. 272-29I.

7 Neumann R. Caracterização tecnológica dos potenciais minérios de terras-raras de Catalão I, GO [tese de doutorado]. São Paulo: Universidade de São Paulo; 1999.

Recebido em: 18 Dez. 2015

Aceito em: II Set. 2016 